\title{
Advances in understanding nociception and neuropathic pain
}

\author{
Ewan St. John Smith ${ }^{1} \mathbb{D}$
}

Received: 14 July 2017 / Revised: 2 October 2017 / Accepted: 3 October 2017 / Published online: 14 October 2017

(C) The Author(s) 2017. This article is an open access publication

\begin{abstract}
Pain results from the activation of a subset of sensory neurones termed nociceptors and has evolved as a "detect and protect" mechanism. However, lesion or disease in the sensory system can result in neuropathic pain, which serves no protective function. Understanding how the sensory nervous system works and what changes occur in neuropathic pain are vital in identifying new therapeutic targets and developing novel analgesics. In recent years, technologies such as optogenetics and RNA-sequencing have been developed, which alongside the more traditional use of animal neuropathic pain models and insights from genetic variations in humans have enabled significant advances to be made in the mechanistic understanding of neuropathic pain.
\end{abstract}

Keywords Chemogenetics · Neurocircuitry $\cdot$ Neuropathic pain $\cdot$ Nociceptor $\cdot$ Optogenetics $\cdot$ Voltage gated sodium channel $(\mathrm{NaV})$

\section{Introduction}

Nociception is the neural process of encoding noxious stimuli, whereas pain is defined as an unpleasant sensory and emotional experience associated with actual or potential tissue damage, or described in terms of such damage [1]. Nociception has been described in a variety of organisms, from the nematode worm Caenorhabditis elegans through to humans, but the case for pain is less clear. Although humans and likely all mammals experience negative emotion, this

Ewan St. John Smith

es336@cam.ac.uk

1 Department of Pharmacology, University of Cambridge, Tennis Court Road, Cambridge CB2 1PD, UK is considered unlikely in C. elegans, but the case for certain organisms, especially fish, is more contentious [2-4]. Numerous reviews have been written about different aspects of pain, from its molecular basis [5-10] and genetic mechanisms [11-13] to its pharmacological treatment [14-16]. The purpose of this review is to discuss how recent insights into pain mechanisms from pre-clinical research may lead to breakthroughs in our understanding, and hopefully treatment, of chronic pain.

Chronic pain is usually defined as regularly occurring pain over a period of several months and it has a prevalence of $\sim 11-19 \%$ of the adult population [17-19]. Broadly speaking, chronic pain can be split into two categories, inflammatory pain and neuropathic pain. Neuropathic pain is pain caused by a lesion or disease of the somatosensory nervous system and a systematic review of epidemiological studies estimates the prevalence of neuropathic pain to be $6.9-10 \%$ [20]. The need for novel therapies to treat neuropathic pain is demonstrated by the analysis of analgesia success. A 2006 report on chronic pain in Europe identified that $64 \%$ of those taking prescription medicine found that their pain medication was at times inadequate, and of the $48 \%$ of chronic pain sufferers not taking pain medication, $14 \%$ had stopped due to side effects [18]. To develop new treatments for neuropathic pain, it is important to first understand the circuitry of pain: how is pain triggered and how is that information transmitted to the central nervous system? To do this, it is necessary to understand how nociceptors function.

\section{Nociceptors: transducers of pain}

The human body is equipped with different types of sensory neurones and nociceptors are the subset that function as the primary unit of pain, being equipped with receptors 
and ion channels that enable the detection of stimuli that have potential to cause damage. When a noxious stimulus activates an ion channel on a nociceptor, for example proton activation of acid-sensing ion channels (ASIC), cation influx depolarises the nociceptor producing a receptor potential. If the receptor potential is of sufficient magnitude to reach the activation threshold for voltage-gated $\mathrm{Na}^{+}$channels $(\mathrm{NaV})$, it will trigger action potential generation and transmission of a pain signal to the spinal cord $[2,5,21]$. In recent years, many new techniques have been developed in pre-clinical research that have accelerated our progress in understanding how nociceptors work and provide tantalising glimpses at their clinical utility. Indeed, such work is essential for both identifying potential new painkiller targets and the developing novel biological treatments for neuropathic pain.

\section{Nociceptor functionality}

Anatomical and in vivo/in vitro electrophysiological data show that some nociceptors are myelinated $\mathrm{A} \delta$-fibres and that others are unmyelinated C-fibres, different subsets of which are sensitive to a different range of stimuli, most being polymodal, but others responding to a narrower range of stimuli $[2,5]$. Recent developments in transgenic mouse and imaging technology have led to elegant in vivo experiments using the genetically encoded $\mathrm{Ca}^{2+}$-indicator GCaMP [22-24], the fluorescence intensity of which is proportional to intracellular $\left[\mathrm{Ca}^{2+}\right]$. In contrast to electrophysiological studies, which suggest a predominantly polymodal nociceptor phenotype, some GCaMP studies have found that under control conditions, most sensory neurones in vivo are actually modality-specific, i.e., they respond to a single noxious stimulus, such as mechanical pinch of the hind paw, but not extreme heat or cold [22, 24]. However, like previous electrophysiology studies, in vivo GCaMP studies have found that injury and inflammation produce increased neuronal responsiveness [22-24]; the increased excitability of sensory neurones observed after injury is likely a key driver of both spontaneous and stimulus-evoked pain experienced by neuropathic pain patients. The discord between electrophysiological and GCaMP studies has been suggested to arise from the invasiveness of in vivo electrophysiological approaches and the trauma of dissociation required for in vitro analysis, both of which may induce inflammation contributing to the induction of nociceptor polymodality [22]. Although a technique that enables simultaneous measurement of multiple sensory neurones, in vivo measurement of intracellular $\left[\mathrm{Ca}^{2+}\right]$ is, however, an indirect method of measuring action potential firing, i.e., signal conduction: not every action potential in a primary afferent fibre necessarily produces a measurable change in intracellular $\left[\mathrm{Ca}^{2+}\right]$ at the cell body and not every change in intracellular $\left[\mathrm{Ca}^{2+}\right]$ will necessarily result from action potential firing. Regardless of the limitations, in vivo $\mathrm{Ca}^{2+}$-imaging provides a powerful tool to enhance our understanding of how the nociceptive system works and the power of genetics means that it will be ever more possible to express a GCaMP indicator in a discrete neuronal subset to selectively determine its contribution to nociception and how this changes in neuropathic pain.

In addition to functional experiments, single-cell RNAsequencing of sensory neurones has shown that neurones can be split into groups according to their transcriptome [25, 26], research that builds on earlier whole DRG RNA-sequencing studies that investigated how neuronal expression profiles change in neuropathic pain [27]. A significant advantage of single-cell RNA-sequencing is the unbiased nature of how data are produced. However, to harness the true power of single-cell RNA-sequencing, it should be conducted on sensory neurones of known anatomical innervation, i.e., through use of retrograde labelling techniques, because this technique has been used to show that neurones innervating different tissues have distinct properties. For example, NaV1.7 is expressed in NaV1.8-positive colonic neurones and yet mice lacking NaV1.7 in NaV1.8-positive neurones although having diminished somatic pain, experience normal visceral pain [28]; articular neurones have smaller acid responses, but greater likelihood of responding to ATP than cutaneous neurones [29], and of all 6 ASIC subunits, ASIC3 mediates acid-excitation of dural, corneal, and cardiac afferents, possibly contributing to the pain of headache, corneal pathologies, and cardiac ischaemia, respectively [30-32].

In the near future, it is likely that retrograde tracing will be coupled with RNA-sequencing to identify the molecular fingerprint of distinct neuronal subsets innervating different tissues. With such information to hand, different proteins and/or neuronal subsets can be targeted using transgenic mouse techniques to determine their contribution to neuropathic pain and thus identify novel analgesic targets.

\section{Unlocking nociceptor circuitry}

Two further techniques recently utilised to further understanding of nociceptor function and circuitry are optogenetics and chemogenetics. Optogenetics involves inducing neuronal expression of light-activated membrane proteins whose activation can enable either depolarisation (e.g., channelrhodopsin-2, ChR2) or hyperpolarisation (e.g., halorhodopsin) to directly switch-on or switch-off neurones, respectively, as well as switching on of $\mathrm{G}$ proteincoupled receptor (GPCR) signalling cascades [33]. By contrast, chemogenetics entails, among other strategies, designer receptors exclusively activated by designer drugs (DREADDs), which are modified GPCRs no longer activated by their endogenous ligand acetylcholine, but instead the biologically inert substance clozapine- $N$-oxide (CNO, 
although recent work suggests that clozapine rather than $\mathrm{CNO}$ is the receptor ligand [34]); differently G proteincoupled DREADDs allow for activation $\left(\mathrm{G}_{\mathrm{s}}\right.$ or $\left.\mathrm{G}_{\mathrm{q}}\right)$ or inhibition $\left(\mathrm{G}_{\mathrm{i}}\right)$ of neuronal function [35]. Using tissue-specific promoters, optogenetic and chemogenetic approaches can target distinct neuronal subsets. For example, plantar paw light stimulation in freely moving mice expressing ChR2 in NaV1.8-positive sensory neurones robustly produced nocifensive behaviours [36]. Like optogenetics, chemogenetics provides the potential to control neuronal function. For example, administration of CNO to mice expressing a $\mathrm{G}_{\mathrm{i}}$-coupled DREADD in sensory neurones known to play a role in heat sensation increased the latency for paw withdrawal from a hot stimulus [37]. However, this study also raised concern about the use of DREADDs, because changes were observed in basal neuronal function, such as alterations in the amplitude of currents mediated by different $\mathrm{NaV}$ subunits. Therefore, results from DREADD studies hold great potential, but should be interpreted with caution and their future clinical use through gene therapy must control for certain risks. An alternative, but similar approach has recently been developed whereby viral transduction of an engineered chloride-channel sensitive to ivermectin ( $\mathrm{GluCl}$ v2.0) was capable of long-term repeatable suppression of sensory neuron sensitivity and amelioration of neuropathic pain in rodents; the expression of GluCl v2.0 in human-induced pluripotent stem cell derived sensory neurones was also shown to cause their silencing in an ivermectin-dependent manner [38]. Overall, the ability to selectively control the excitability of neuronal subpopulations using either chemo- or optogenetic tools offers an attractive way of treating neuropathic pain compared to orally taken medications, which result in the whole body being exposed to the drug. Although such manipulations are likely still some way off, clinical trials for using ChR2 to treat advanced retinitis pigmentosa are underway [39].

Optogenetics and chemogenetics are also being used to further understanding about the circuitry of pain. In 1965, Melzack and Wall published the landmark paper Pain Mechanisms: a new theory, part of which suggested that input from low-threshold mechanoreceptors (LTMRs) inhibits nociceptor neurotransmission in the spinal cord [40]. Optogenetics has shown that ChR2 activation in a subset of myelinated A-fibre nociceptors required for mechanonociception produces an exaggerated pain response, which was mitigated when ChR2 was simultaneously expressed in LTMRs [41]. Co-activation of mechanonociceptors and LTMRs also resulted in fewer superficial dorsal horn neurones being activated compared to when mechanonociceptors were activated alone, which lends further support to Melzack and Wall's theory that LTMR activation inhibits nociception. Studies such as this demonstrate the power of optogenetics for unravelling nociceptor neuronal circuitry, and in the next few years, optogenetics will likely be applied to determining how nociceptor circuitry becomes altered in neuropathic pain, which may identify potentially novel routes of analgesia, as well as, perhaps, providing explanations for side effects associated with current interventions.

\section{Clinical insights into neuropathic pain from pre-clinical research}

As described in the Introduction, neuropathic pain is common and chronic pain sufferers often receive inadequate pain relief from current medications. A 2015 meta-analysis of trials looking at pharmacological treatments for neuropathic pain identified that although there is strong recommendation for the use of certain drugs (e.g., gabapentin, pregabalin, serotonin/noradrenaline reuptake inhibitors, and tricyclic antidepressants), the effects are relatively modest: the number needed to treat (NNT) to produce a $50 \%$ reduction in pain for those drugs with strong recommendation for use ranges from 3.6 to 7.7 , i.e., $4-8$ patients must be treated for one patient to experience at least $50 \%$ pain reduction when the placebo response is subtracted [42]. In addition to pharmacological treatment, a variety of other interventions are available for neuropathic pain, including: physical and psychological therapies, spinal cord stimulation, surgery, and transcranial magnetic stimulation (TMS), but here, discussion will be focused on the potential for the development of novel pharmacotherapy resulting from enhanced understanding of the molecular basis of neuropathic pain.

\section{Pre-clinical animal models}

A major problem with regard to studying and treating neuropathic pain is its highly variable aetiology, ranging from brain lesions to demyelinating diseases of the spinal cord, and peripheral neuropathy resulting from conditions such as diabetes mellitus or as a result of anti-cancer chemotherapy. Pre-clinically, most studies are conducted on rodents and involve direct nerve injury, often to the sciatic nerve, which, although bearing poor resemblance to the case history of most neuropathic pain patients, does enable disease processes to be investigated and many treatments used clinically are able to reverse the pain behaviours observed in these models [43]. In addition to surgical models, there are also animal models that more closely resemble human disease pathogenesis, e.g., diabetic neuropathy [44] and certain chemotherapy treatments [45]. However, there has been a long-standing problem in efficiently translating analgesics from animal models through to the clinic, either due to lack of efficacy or due to side effects [46]. There are 
several potential reasons that have hindered translation of drugs, including: the highly varied aetiology of neuropathic pain in humans compared to the relatively restricted animal models, the in-bred (and thus genetically homogenous) animal subjects compared to the more genetically heterogeneous human population, and the difference in how pain assessed, i.e., most animal studies measure stimulus-evoked withdrawal behaviours, whereas neuropathic pain patients will often describe spontaneous pain. From the animal pain model perspective, it would, therefore, be advantageous to develop paradigms that measure changes in normal behaviour, e.g., suppression of burrowing can occur as a result of pain-induced changes in general well-being [47], alongside measurements of evoked pain. At the same time, it is, perhaps, necessary to try and better identify groups of patients for which a potential novel therapy may be of benefit when recruiting for clinical trials. Recent multicentre clustering analysis of quantitative sensory testing parameters measured in patients with different aetiologies has identified three distinct patient subgroups (sensory loss, thermal hyperalgesia and mechanical hyperalgesia), which may be underpinned by distinct pathological mechanisms. Thus, this may help to stratify patients for clinical trials testing analgesics arising from animal models where the mechanism of action is often well understood [48]. Subsequently, an algorithm has been developed to allocate patients to each subgroup, which should aid the stratification of patients both with regard to identifying appropriate patients for clinical trials and may enable easier identification of an individual patient's optimal treatment regime [49].

Although animal models of neuropathic pain have their limitations and translation is currently far from perfect, such models have identified changes at all levels in the pain pathway in neuropathic pain, from alterations in sensory neurone protein expression to changes in spinal cord synaptic function and in the descending control of pain from the brain, some of which will now be discussed to shed light on potential future medications.

\section{Targeting action potential electrogenesis}

From a therapeutic point of view, cutting off pain signals within the primary afferent nociceptor might be predicted to have fewer side effects than targeting a process within the central nervous system. To validate this approach, injection of the local anaesthetic lidocaine, which blocks all $\mathrm{NaV}$ subunits, at painful foci in patients suffering from painful neuropathy greatly diminished allodynia, suggesting that ongoing nociceptor input drives neuropathic pain [50]. What makes targeting of $\mathrm{NaV}$ subunits particularly appealing is that some neuropathic pain patients experience pain as a result of gain-of-function $\mathrm{NaV}$ mutations (for a review of these and other pain-related mutations, see [11-13]). The
NaV1.7 subunit is commonly affected, mutations often causing a shift in the activation threshold (a smaller stimulus evokes pain) and/or slow inactivation (once activated the nerve fires for longer) [51, 52]. There are also NaV1.7 mutations that produce congenital insensitivity to pain [53, 54], but are not associated with serious systemic side effects (likely due to $\mathrm{NaV} 1.7$ expression being largely restricted to the peripheral nervous system), which suggests that selective inhibition of $\mathrm{NaV} 1.7$ could result in pain relief without producing a plethora of neurological side effects. Transgenic mouse models where NaV1.7 has been deleted in different neuronal subsets have demonstrated its critical contribution to different forms of pain [55], and recent work suggests that NaV1.7 activity also regulates endogenous opioid release, such that combining an NaV1.7 inhibitor with an opioid may provide synergistic analgesia with fewer side effects [56]. A recent Phase 2a trial in trigeminal neuralgia patients demonstrated that the selective NaV1.7 inhibitor BIIB074 produced fewer treatment failures than placebo and a better improvement in the daily pain score than placebo during the double-blind phase [57], results that are encouraging, but clearly larger trials are needed, especially those aimed at determining if BIIB074 is actually more efficacious and/or provides a lower side effect burden than the current first-line medications for trigeminal neuralgia, such as carbamazepine. Mutations in NaV1.8 can also underlie painful neuropathy in humans [58] and transgenic mouse work has identified a critical role for NaV1.8 in acute cold pain $[59,60]$, as well as cold allodynia in some neuropathic pain models [61]. Finally, mutations in NaV1.9 can cause both congenital insensitivity to pain [62] and painful neuropathy [63] in humans, and transgenic mouse work supports a role for NaV1.9 in inflammatory [64], neuropathic [61], and visceral pain [65], suggesting that like $\mathrm{NaV} 1.7$ and $\mathrm{NaV1.8}$, $\mathrm{NaV} 1.9$ could be targeted to produce pain relief in certain neuropathic pain conditions. However, a key challenge for targeting any $\mathrm{NaV}$ subunit is to develop high enough subunit specificity to avoid off-target effects (e.g., inhibition of cardiac NaV1.5); a future possibility may be target modulators of $\mathrm{NaV}$ alpha subunits, rather than the alpha subunits themselves, for example beta subunits that modulate alpha subunit biophysical activity [66]. By contrast with inhibiting $\mathrm{NaV}$ subunits, there are numerous voltage-gated potassium channels $(\mathrm{Kv})$ involved in sensory neurone action potential generation, which could also be targeted by a channel opener drug to relieve neuropathic pain $[67,68]$. One promising example is retigabine, which is a $\mathrm{Kv} 7$ opener used as an anticonvulsant, but has also been shown to attenuate neuropathic pain in rodents [69]. However, a recent clinical trial looking at the effects of retigabine for treating postherpetic neuralgia, failed to find any difference compared to placebo in the primary endpoint of a change from baseline in the average pain score in the last 7 days of the maintenance phase [70]. 
In terms of action potential transmission, hyperpolarisation activated, cyclic nucleotide-gated ion channel (HCN) subunits are activated during the repolarization phase of action potential firing and are critical in returning a neurone to its resting membrane potential. The $\mathrm{HCN} 2$ subunit is predominantly expressed in sensory neurones and can be modulated by cyclic adenosine monophosphate (cAMP) to fire at more depolarised potentials, which induces trains of action potential firing [71]. The modulation of HCN2 by cAMP may well be important, because mice lacking HCN2 in a subset of sensory neurones fail to develop neuropathic pain [72] and ivabradine, which is a non-selective, peripherally restricted anti-anginal drug, reverses neuropathic pain in mice as effectively as gabapentin [73]. To date, however, no clinical trials have been published on the use of ivabradine for neuropathic pain. A potential complication lies in ivabradine's non-selectivity, such that its blockade of cardiac HCN4 produces bradycardia at similar doses to those producing a relief from neuropathic pain [73], and thus, the search is on for a selective HCN2 inhibitor.

\section{Targeting transduction}

As an alternative to reducing action potential firing through $\mathrm{NaV}$ or $\mathrm{HCN}$ blockade, the nociceptor transduction process itself could be disrupted. Mechanical hyperalgesia/allodynia is common features of neuropathic pain [48] and, in recent years, progress has been made in understanding how sensory neurones are activated by mechanical stimuli $[74,75]$. The mechanically activated ion channel Piezo2 is necessary for normal touch sensitivity, but it is not involved in detecting noxious mechanical forces or in inflammatory mechanical hyperalgesia in mice [76]; it is, however, sensitised by signalling pathways associated with neuropathic pain [77]. Although Piezo ion channels are intrinsically mechanosensitive [78], the activation threshold for Piezo2 is reduced by stomatin-like protein 3 (STOML3) [79]. Studies in mice have shown that neuronal mechanosensitivity is lowered in neurones from mice lacking STOML3 $[79,80]$, that neuronal STOML3 expression is elevated in mouse neuropathic pain models [81] and mice lacking STOML3 show greatly reduced mechanical allodynia in neuropathic pain models [80, 81], i.e., targeting STOML3 may act to relieve the mechanical allodynia associated with neuropathic pain. The modulation of cellular mechanosensitivity by STOML3 is dependent upon its ability to form oligomers [79] and recent research identified two compounds that prevent oligomerisation and reverse neuropathic pain in mice [81], which highlights the tractability of such protein-protein interactions for pharmacotherapy. Compounds disrupting STOML3 oligomerisation prevented mechanical allodynia not only in nerve injury models, but also in a model of diabetic neuropathy [81], which raises hopes of possibly developing this therapeutic avenue for treating patients with diabetic neuropathy who experience a range of disturbances in mechanosensitivity, including dynamic mechanical allodynia [82].

\section{Interfering with central processing}

In addition to targeting the primary afferent sensory neurone itself, an alternative is to target spinal cord neurotransmission between first- and second-order neurones. The CaV2.2 inhibitor ziconotide is used in the treatment of neuropathic pain and acts by blocking presynaptic $\mathrm{CaV}$ subunits to inhibit neurotransmission [83]. A major drawback is that to prevent systemic side effects, ziconotide must be administered intrathecally, which requires the implantation of a minipump. By determining the spinal cord pathology in neuropathic pain, it is hoped that more targeted therapies could be developed. Using rodent neuropathic pain models, it has been shown that the expression of glutamic acid decarboxylase (GAD, which synthesises the inhibitory neurotransmitter $\gamma$-aminobutyric acid, GABA) decreases following nerve injury [84]. Furthermore, some [85] but not all [86] studies have found that the number of GABAergic neurones decreases in neuropathic pain. With lowered GABAergic tone likely contributing to neuropathic pain it is thought that therapies which normalise GABAergic neurotransmission may be beneficial. Indeed, in rodents, positive modulation of

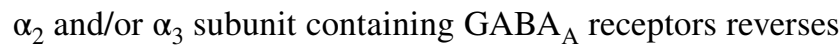
neuropathic pain [87]. However, a potential limitation of drugs that target $\mathrm{GABA}_{\mathrm{A}}$ receptors is that they are widely expressed in the brain and thus may potentially produce unwanted side effects. To bypass this problem, recent work has shown that progenitors of GABAergic neurones can be transplanted into the spinal cord and integrate with the spinal cord circuitry to reverse nerve injury-induced and chemotherapy-induced neuropathic pain [88, 89]; unlike systemic injection of GABA receptor modulators that may modulate off-target GABAergic function, no migration of the progenitors outside of the segment into which injections were made was observed, thus diminishing the potential for side effects. Finally, over the last 15 years, research from several groups has also demonstrated a key interaction between spinal cord microglia and GABAergic function in neuropathic pain. Following the induction of neuropathic pain in rodents, spinal cord microglia are activated [90], and release brain-derived neurotrophic factor (BDNF) [91], which decreases neuronal $\mathrm{K}^{+} / \mathrm{Cl}^{-}$co-transporter 2 (KCC2) expression [92]. Lowered $\mathrm{KCC} 2$ expression shifts the $\mathrm{Cl}^{-}$concentration gradient, such that $\mathrm{GABA}_{\mathrm{A}}$ receptor activation no longer causes inhibition, but can actually cause excitation of projection neurones 
[93]. An experimental compound has been identified that increases KCC2 surface expression, which normalises the intracellular $\mathrm{Cl}^{-}$concentration, reverses mechanical allodynia in rats, and validates the prospect of targeting $\mathrm{KCC} 2$ to produce analgesia in neuropathic pain [94].

As well as diminished central inhibitory function in neuropathic pain, central circuits become hyperexcitable and understanding the mechanisms involved offers further potential for identifying new druggable targets for treating neuropathic pain [95]. One key process is long-term potentiation (LTP), an increase in synaptic strength following an elevated level of primary afferent input, which involves the glutamate $N$-methyl-D-aspartate (NMDA) receptor [96]. However, NMDA receptors are present throughout the nervous system and the non-analgesic effects of the recreational drug ketamine that blocks NMDA receptor activity (e.g., hallucinations and memory impairment), which demonstrate that systemic blockade of NMDA receptors is not a feasible route for standard neuropathic pain treatment, as such a peripherally restricted approach is likely to be necessary.

\section{Conclusions}

In summary, neuropathic pain is a common condition with highly variably aetiology and for which the current treatments are often inefficacious and/or produce severe side effects. Pre-clinical research, largely using rodent models, but recently driven by human genetics, is focused on understanding how the nervous system changes during neuropathic pain in an effort to identify novel targets for analgesia and to validate their druggability. Rapid advances in technology have resulted in the development of many novel tools, such as chemo- and optogenetics, which will be applied to make further inroads into the pathogenesis of neuropathic pain using animal models, as well as having the potential to be developed clinically as highlighted by the current clinical trials with $\mathrm{ChR} 2$ in advanced retinitis pigmentosa. Finally, work in recent years has already identified several novel drug targets, such as NaV1.7, HCN2, STOML3, and KCC2, and future clinical trials will determine their true potential as targets for novel analgesics.

Acknowledgements I acknowledge funding from Arthritis Research UK (Grant Reference 20930) and the Rosetrees Trust (Grant Reference A1296), which support pain research in my group. I also acknowledge Drs. Gerard Callejo and James Hockley, as well as Reviewers, for expert critique of the manuscript.

\section{Compliance with ethical standards}

Conflicts of interest I have no conflict of interest.

Ethical statement No human or animal research was conducted in writing this review.
Open Access This article is distributed under the terms of the Creative Commons Attribution 4.0 International License (http://creativecommons.org/licenses/by/4.0/), which permits unrestricted use, distribution, and reproduction in any medium, provided you give appropriate credit to the original author(s) and the source, provide a link to the Creative Commons license, and indicate if changes were made.

\section{References}

1. IASP Taxonomy. http://www.iasp-pain.org/Taxonomy. Accessed 15 May 2017

2. Smith ES, Lewin GR (2009) Nociceptors: a phylogenetic view. J Comp Physiol A 195:1089-1106. doi:10.1007/s00359-009-0482-z

3. Sneddon LU (2015) Pain in aquatic animals. J Exp Biol 218:967976. doi: $10.1242 /$ jeb. 088823

4. Crook RJ, Walters ET (2011) Nociceptive behavior and physiology of molluscs: animal welfare implications. ILAR J 52:185-195

5. Dubin AE, Patapoutian A (2010) Nociceptors: the sensors of the pain pathway. J Clin Investig 120:3760-3772. doi:10.1172/ JCI42843

6. Kuner R, Flor H (2016) Structural plasticity and reorganisation in chronic pain. Nat Rev Neurosci 18:20-30. doi:10.1038/ nrn.2016.162

7. Todd AJ (2010) Neuronal circuitry for pain processing in the dorsal horn. Nat Rev Neurosci 11:823-836. doi:10.1038/nrn2947

8. Gold MS, Gebhart GF (2010) Nociceptor sensitization in pain pathogenesis. Nat Med 16:1248-1257. doi:10.1038/nm.2235

9. Basbaum AI, Bautista DM, Scherrer G, Julius D (2009) Cellular and molecular mechanisms of pain. Cell 139:267-284. doi:10.1016/j.cell.2009.09.028

10. Lewin GR, Lechner SG, Smith ESJ (2014) Nerve growth factor and nociception: from experimental embryology to new analgesic therapy. Handb Exp Pharmacol 220:251-282

11. Dib-Hajj SD, Waxman SG (2014) Translational pain research: Lessons from genetics and genomics. Sci Transl Med 6:249sr4. doi:10.1126/scitranslmed.3007017

12. Bennett DLH, Woods CG (2014) Painful and painless channelopathies. Lancet Neurol 13:587-599. doi:10.1016/ S1474-4422(14)70024-9

13. Sommer C (2016) Exploring pain pathophysiology in patients. Science 354:588-592. doi:10.1126/science.aaf8935

14. Calabrò A, Caterino AL, Elefante E et al (2016) One year in review 2016: novelties in the treatment of rheumatoid arthritis. Clin Exp Rheumatol 34:357-372

15. Colloca L, Ludman T, Bouhassira D et al (2017) Neuropathic pain. Nat Rev Dis Primers 3:17002. doi:10.1038/nrdp.2017.2

16. Mathew E, Kim E, Zempsky W (2016) Pharmacologic treatment of pain. Semin Pediatr Neurol 23:209-219. doi:10.1016/j. spen.2016.10.004

17. Nahin RL (2015) Estimates of pain prevalence and severity in adults: United States, 2012. J Pain 16:769-780. doi:10.1016/j. jpain.2015.05.002

18. Breivik H, Collett B, Ventafridda V et al (2006) Survey of chronic pain in Europe: prevalence, impact on daily life, and treatment. Eur J Pain 10:287-333

19. Riskowski JL (2014) Associations of socioeconomic position and pain prevalence in the United States: findings from the National Health and Nutrition Examination Survey. Pain Med 15:15081521. doi:10.1111/pme. 12528

20. van Hecke O, Austin SK, Khan RA et al (2014) Neuropathic pain in the general population: a systematic review of epidemiological studies. Pain 155:654-662. doi:10.1016/j.pain.2013.11.013 
21. Reichling DB, Green PG, Levine JD (2013) The fundamental unit of pain is the cell. Pain 154:S2-S9. doi:10.1016/j. pain.2013.05.037

22. Emery EC, Luiz AP, Sikandar S et al (2016) In vivo characterization of distinct modality-specific subsets of somatosensory neurons using GCaMP. Sci Adv 2:e1600990. doi:10.1126/ sciadv. 1600990

23. Smith-Edwards KM, DeBerry JJ, Saloman JL et al (2016) Profound alteration in cutaneous primary afferent activity produced by inflammatory mediators. eLife. doi:10.7554/eLife.20527

24. Kim YS, Anderson M, Park K et al (2016) Coupled activation of primary sensory neurons contributes to chronic pain. Neuron 91:1085-1096. doi:10.1016/j.neuron.2016.07.044

25. Li C-L, Li K-C, Wu D et al (2016) Somatosensory neuron types identified by high-coverage single-cell RNA-sequencing and functional heterogeneity. Cell Res 26:83-102. doi:10.1038/cr.2015.149

26. Usoskin D, Furlan A, Islam S et al (2014) Unbiased classification of sensory neuron types by large-scale single-cell RNA sequencing. Nat Neurosci 18:145-153. doi:10.1038/nn.3881

27. Perkins JR, Antunes-Martins A, Calvo M et al (2014) A comparison of RNA-seq and exon arrays for whole genome transcription profiling of the L5 spinal nerve transection model of neuropathic pain in the rat. Mol Pain 10:7. doi:10.1186/1744-8069-10-7

28. Hockley JRF, González-Cano R, McMurray S et al (2017) Visceral and somatic pain modalities reveal $\mathrm{Na}_{\mathrm{V}}$ 1.7-independent visceral nociceptive pathways. J Physiol 595:2661-2679. doi:10.1113/JP272837

29. da Silva Serra I, Husson Z, Bartlett JD, Smith ESJ (2016) Characterization of cutaneous and articular sensory neurons. Mol Pain. doi:10.1177/1744806916636387

30. Yan J, Wei X, Bischoff C et al (2013) pH-evoked dural afferent signaling is mediated by ASIC 3 and is sensitized by mast cell mediators. Headache 53:1250-1261. doi:10.1111/head.12152

31. Immke DC, McCleskey EW (2001) Lactate enhances the acidsensing $\mathrm{Na}^{+}$channel on ischemia-sensing neurons. Nat Neurosci 4:869-870

32. Callejo G, Castellanos A, Castany M et al (2015) Acid-sensing ion channels detect moderate acidifications to induce ocular pain. Pain 156:483-495. doi:10.1097/01.j.pain.0000460335.49525.17

33. Czapiński J, Kiełbus M, Kałafut J et al (2017) How to train a cell—cutting-edge molecular tools. Front Chem. doi:10.3389/ fchem.2017.00012

34. Gomez JL, Bonaventura J, Lesniak W et al (2017) Chemogenetics revealed: DREADD occupancy and activation via converted clozapine. Science 357:503-507. doi:10.1126/science.aan2475

35. Roth BL (2016) DREADDs for neuroscientists. Neuron 89:683694. doi:10.1016/j.neuron.2016.01.040

36. Daou I, Tuttle AH, Longo G et al (2013) Remote optogenetic activation and sensitization of pain pathways in freely moving mice. J Neurosci 33:18631-18640. doi:10.1523/ JNEUROSCI.2424-13.2013

37. Saloman JL, Scheff NN, Snyder LM et al (2016) Gi-DREADD expression in peripheral nerves produces ligand-dependent analgesia, as well as ligand-independent functional changes in sensory neurons. J Neurosci 36:10769-10781. doi:10.1523/ JNEUROSCI.3480-15.2016

38. Weir GA, Middleton SJ, Clark AJ et al (2017) Using an engineered glutamate-gated chloride channel to silence sensory neurons and treat neuropathic pain at the source. Brain. doi:10.1093/ brain/awx 201

39. RST-001 phase I/II trial for advanced retinitis pigmentosa. Allergan (2015). https://clinicaltrials.gov/ct2/show/NCT02556736

40. Melzack R, Wall PD (1965) Pain mechanisms: a new theory. Science 150:971-979

41. Arcourt A, Gorham L, Dhandapani R et al (2017) Touch receptorderived sensory information alleviates acute pain signaling and fine-tunes nociceptive reflex coordination. Neuron 93:179-193. doi:10.1016/j.neuron.2016.11.027

42. Finnerup NB, Attal N, Haroutounian S et al (2015) Pharmacotherapy for neuropathic pain in adults: a systematic review and meta-analysis. Lancet Neurol 14:162-173. doi:10.1016/ S1474-4422(14)70251-0

43. Burma NE, Leduc-Pessah H, Fan CY, Trang T (2017) Animal models of chronic pain: advances and challenges for clinical translation: animal models of chronic pain. J Neurosci Res 95:12421256. doi:10.1002/jnr.23768

44. Gao F, Zheng Z (2014) Animal models of diabetic neuropathic pain. Exp Clin Endocrinol Diabetes 122:100-106. doi:10.105 5/s-0033-1363234

45. Hama A, Takamatsu H (2016) Chemotherapy-induced peripheral neuropathic pain and rodent models. CNS Neurol Disord Drug Targets 15:7-19

46. Mao J (2012) Current challenges in translational pain research. Trends Pharmacol Sci 33:568-573. doi:10.1016/j.tips.2012.08.001

47. Wodarski R, Delaney A, Ultenius C et al (2016) Cross-centre replication of suppressed burrowing behaviour as an ethologically relevant pain outcome measure in the rat: a prospective multicentre study. Pain 157:2350-2365. doi:10.1097/j. pain.0000000000000657

48. Baron R, Maier C, Attal N et al (2017) Peripheral neuropathic pain: a mechanism-related organizing principle based on sensory profiles. Pain 158:261-272. doi:10.1097/j. pain.0000000000000753

49. Vollert J, Maier C, Attal N et al (2017) Stratifying patients with peripheral neuropathic pain based on sensory profiles: algorithm and sample size recommendations. Pain 158:1446-1455. doi:10.1097/j.pain.0000000000000935

50. Gracely RH, Lynch SA, Bennett GJ (1992) Painful neuropathy: altered central processing maintained dynamically by peripheral input. Pain 51:175-194

51. Cummins TR, Dib-Hajj SD, Waxman SG (2004) Electrophysiological properties of mutant Nav1.7 sodium channels in a painful inherited neuropathy. J Neurosci 24:8232-8236. doi:10.1523/JNEUROSCI.2695-04.2004

52. Fertleman CR, Baker MD, Parker KA et al (2006) SCN9A mutations in paroxysmal extreme pain disorder: allelic variants underlie distinct channel defects and phenotypes. Neuron 52:767-774. doi:10.1016/j.neuron.2006.10.006

53. Cox JJ, Reimann F, Nicholas AK et al (2006) An SCN9A channelopathy causes congenital inability to experience pain. Nature 444:894-898. doi:10.1038/nature05413

54. Emery EC, Habib AM, Cox JJ et al (2015) Novel SCN9A mutations underlying extreme pain phenotypes: unexpected electrophysiological and clinical phenotype correlations. J Neurosci 35:7674-7681. doi:10.1523/JNEUROSCI.3935-14.2015

55. Minett MS, Nassar MA, Clark AK et al (2012) Distinct Nav1.7dependent pain sensations require different sets of sensory and sympathetic neurons. Nat Commun 3:791. doi:10.1038/ ncomms 1795

56. Minett MS, Pereira V, Sikandar S et al (2015) Endogenous opioids contribute to insensitivity to pain in humans and mice lacking sodium channel Nav1.7. Nat Commun 6:8967. doi:10.1038/ ncomms 9967

57. Zakrzewska JM, Palmer J, Morisset V et al (2017) Safety and efficacy of a Nav1.7 selective sodium channel blocker in patients with trigeminal neuralgia: a double-blind, placebo-controlled, randomised withdrawal phase 2 a trial. Lancet Neurol 16:291300. doi:10.1016/S1474-4422(17)30005-4

58. Faber CG, Lauria G, Merkies ISJ et al (2012) Gain-of-function Nav1.8 mutations in painful neuropathy. Proc Natl Acad Sci 109:19444-19449. doi:10.1073/pnas.1216080109 
59. Zimmermann K, Leffler A, Babes A et al (2007) Sensory neuron sodium channel Nav1.8 is essential for pain at low temperatures. Nature 447:856-859. doi:10.1038/nature05880

60. Abrahamsen B, Zhao J, Asante CO et al (2008) The cell and molecular basis of mechanical, cold, and inflammatory pain. Science 321:702-705. doi:10.1126/science.1156916

61. Minett MS, Falk S, Santana-Varela S et al (2014) Pain without nociceptors? Nav1.7-independent pain mechanisms. Cell Rep 6:301-312. doi:10.1016/j.celrep.2013.12.033

62. Leipold E, Liebmann L, Korenke GC et al (2013) A de novo gain-of-function mutation in SCN11A causes loss of pain perception. Nat Genet 45:1399-1404. doi:10.1038/ng.2767

63. Huang J, Han C, Estacion M et al (2014) Gain-of-function mutations in sodium channel NaV1.9 in painful neuropathy. Brain 137:1627-1642. doi:10.1093/brain/awu079

64. Priest BT, Murphy BA, Lindia JA et al (2005) Contribution of the tetrodotoxin-resistant voltage-gated sodium channel NaV1.9 to sensory transmission and nociceptive behavior. Proc Natl Acad Sci USA 102:9382-9387

65. Hockley JRF, Boundouki G, Cibert-Goton V et al (2014) Multiple roles for NaV1.9 in the activation of visceral afferents by noxious inflammatory, mechanical, and human disease-derived stimuli. Pain 155:1962-1975. doi:10.1016/j.pain.2014.06.015

66. Namadurai S, Yereddi NR, Cusdin FS et al (2015) A new look at sodium channel subunits. Open Biol 5:140192. doi:10.1098/ rsob. 140192

67. Busserolles J, Tsantoulas C, Eschalier A, López García JA (2016) Potassium channels in neuropathic pain: advances, challenges, and emerging ideas. Pain 157(Suppl 1):S7-S14. doi:10.1097/j. pain.0000000000000368

68. Du X, Gao H, Jaffe D et al (2017) M-type $\mathrm{K}(+)$ channels in peripheral nociceptive pathways. Br J Pharmacol. doi:10.1111/ bph. 13978

69. Blackburn-Munro G, Jensen BS (2003) The anticonvulsant retigabine attenuates nociceptive behaviours in rat models of persistent and neuropathic pain. Eur J Pharmacol 460:109-116

70. Valeant Pharmaceuticals International, Inc (2011) Safety/efficacy study of retigabine vs. placebo in post-herpetic neuralgia (PHN). In: ClinicalTrials.gov. https://clinicaltrials.gov/ct2/show/results/ NCT00612105 sect $=X 756 \&$ term $=$ retigabine $\&$ draw $=3 \&$ rank $=$ 19\#outcome1. Accessed 7 Nov 2017

71. Momin A, Cadiou H, Mason A, McNaughton PA (2008) Role of the hyperpolarization-activated current Ih in somatosensory neurons. J Physiol 586:5911-5929

72. Emery EC, Young GT, Berrocoso EM et al (2011) HCN2 ion channels play a central role in inflammatory and neuropathic pain. Science 333:1462-1466. doi:10.1126/science.1206243

73. Young GT, Emery EC, Mooney ER et al (2014) Inflammatory and neuropathic pain are rapidly suppressed by peripheral block of hyperpolarisation-activated cyclic nucleotide-gated ion channels. Pain 155:1708-1719. doi:10.1016/j.pain.2014.05.021

74. Poole K, Moroni M, Lewin GR (2015) Sensory mechanotransduction at membrane-matrix interfaces. Pflug Arch 467:121-132. doi:10.1007/s00424-014-1563-6

75. Ranade SS, Syeda R, Patapoutian A (2015) Mechanically activated ion channels. Neuron 87:1162-1179. doi:10.1016/j. neuron.2015.08.032

76. Ranade SS, Woo S-H, Dubin AE et al (2014) Piezo2 is the major transducer of mechanical forces for touch sensation in mice. Nature 516:121-125. doi:10.1038/nature13980

77. Eijkelkamp N, Linley JE, Torres JM et al (2013) A role for Piezo2 in EPAC1-dependent mechanical allodynia. Nat Commun 4:1682. doi: $10.1038 /$ ncomms 2673

78. Syeda R, Florendo MN, Cox CD et al (2016) Piezo1 channels are inherently mechanosensitive. Cell Rep 17:1739-1746. doi:10.1016/j.celrep.2016.10.033
79. Poole K, Herget R, Lapatsina L et al (2014) Tuning Piezo ion channels to detect molecular-scale movements relevant for fine touch. Nat Commun 5:3520. doi:10.1038/ncomms4520

80. Wetzel C, Hu J, Riethmacher D et al (2007) A stomatin-domain protein essential for touch sensation in the mouse. Nature 445:206-209

81. Wetzel C, Pifferi S, Picci C et al (2016) Small-molecule inhibition of STOML3 oligomerization reverses pathological mechanical hypersensitivity. Nat Neurosci 20:209-218. doi:10.1038/nn.4454

82. Themistocleous AC, Ramirez JD, Shillo PR et al (2016) The Pain in Neuropathy Study (PiNS): a cross-sectional observational study determining the somatosensory phenotype of painful and painless diabetic neuropathy. Pain 157:1132-1145. doi:10.1097/j. pain.0000000000000491

83. Zamponi GW (2015) Targeting voltage-gated calcium channels in neurological and psychiatric diseases. Nat Rev Drug Discov 15:19-34. doi:10.1038/nrd.2015.5

84. Eaton MJ, Plunkett JA, Karmally S et al (1998) Changes in GAD- and GABA-immunoreactivity in the spinal dorsal horn after peripheral nerve injury and promotion of recovery by lumbar transplant of immortalized serotonergic precursors. J Chem Neuroanat 16:57-72

85. Scholz J (2005) Blocking caspase activity prevents transsynaptic neuronal apoptosis and the loss of inhibition in lamina II of the dorsal horn after peripheral nerve injury. J Neurosci 25:73177323. doi:10.1523/JNEUROSCI.1526-05.2005

86. Polgár E, Hughes DI, Riddell JS et al (2003) Selective loss of spinal GABAergic or glycinergic neurons is not necessary for development of thermal hyperalgesia in the chronic constriction injury model of neuropathic pain. Pain 104:229-239

87. Knabl J, Witschi R, Hösl K et al (2008) Reversal of pathological pain through specific spinal GABAA receptor subtypes. Nature 451:330-334. doi:10.1038/nature06493

88. Bráz JM, Sharif-Naeini R, Vogt D et al (2012) Forebrain GABAergic neuron precursors integrate into adult spinal cord and reduce injury-induced neuropathic pain. Neuron 74:663-675. doi:10.1016/j.neuron.2012.02.033

89. Bráz JM, Wang X, Guan Z et al (2015) Transplant-mediated enhancement of spinal cord GABAergic inhibition reverses paclitaxel-induced mechanical and heat hypersensitivity. Pain 156:1084-1091. doi:10.1097/j.pain.0000000000000152

90. Tsuda M, Shigemoto-Mogami Y, Koizumi S et al (2003) P2X4 receptors induced in spinal microglia gate tactile allodynia after nerve injury. Nature 424:778-783. doi:10.1038/nature01786

91. Coull JAM, Beggs S, Boudreau D et al (2005) BDNF from microglia causes the shift in neuronal anion gradient underlying neuropathic pain. Nature 438:1017-1021. doi:10.1038/nature04223

92. Rivera $\mathrm{C}$ (2002) BDNF-induced TrkB activation down-regulates the $\mathrm{K}^{+}-\mathrm{Cl}^{-}$cotransporter $\mathrm{KCC} 2$ and impairs neuronal $\mathrm{Cl}^{-}$extrusion. J Cell Biol 159:747-752. doi:10.1083/jcb.200209011

93. Coull JAM, Boudreau D, Bachand K et al (2003) Trans-synaptic shift in anion gradient in spinal lamina I neurons as a mechanism of neuropathic pain. Nature 424:938-942. doi:10.1038/ nature 01868

94. Gagnon M, Bergeron MJ, Lavertu G et al (2013) Chloride extrusion enhancers as novel therapeutics for neurological diseases. Nat Med 19:1524-1528. doi:10.1038/nm.3356

95. Sandkühler J, Lee J (2013) How to erase memory traces of pain and fear. Trends Neurosci 36:343-352. doi:10.1016/j. tins.2013.03.004

96. Ikeda H, Heinke B, Ruscheweyh R, Sandkühler J (2003) Synaptic plasticity in spinal lamina I projection neurons that mediate hyperalgesia. Science 299:1237-1240. doi:10.1126/science.1080659 